\title{
ADULT SPINE DEFORMITY - AN OVERVIEW OF RADIOGRAPHIC AND CLINICAL CONSIDERATIONS
}

\author{
DEFORMIDADE DA COLUNA VERTEBRAL DO ADULTO - PANORAMA DAS CONSIDERAÇÕES \\ CLIINICAS E RADIOGRÁFICAS
}

\section{DEFORMIDAD DE LA COLUMNA VERTEBRAL DEL ADULTOS - VISIÓN GENERAL DE LAS CONSIDERACIONES CLIINICAS Y RADIOGRÁFICAS}

\author{
Raphael Pratali1, Bassel Diebo², Frank Schwab ${ }^{2}$ \\ 1. Hospital do Servidor Público Estadual de São Paulo, Orthopedics andTraumatology Service, São Paulo, SP, Brazil. \\ 2. Hospital for Special Surgery, Spine Service, NewYork, NY, USA.
}

\begin{abstract}
Adult spine deformity is a complex pathology that represents a public health problem with a deep impact on society. When evaluating the patient, not only the clinical and radiographic aspects are essential, but also the clear understanding of the specific needs and expectations of the individual. To elaborate the treatment plan it is necessary to quantify the pain and disability, as well as the spinopelvic alignment of the patient, including the mechanisms that may be recruited to compensate for deformity. Considering these factors, it is possible to define objectives for the surgical correction in order to obtain clinical improvement.
\end{abstract}

Keywords: Scoliosis; Aging; Classification; Bone malalignment.

\section{RESUMO}

A deformidade da coluna vertebral do adulto é uma patologia complexa que representa um problema de saúde pública com profundo impacto na sociedade. Ao avaliar o paciente, não só os aspectos clínicos e radiográficos são essenciais, mas também o claro entendimento das necessidades e expectativas do indivíduo. Para elaborar o plano de tratamento, é necessário quantificar a dor e incapacidade do paciente, além do alinhamento espinopélvico, incluindo-se os mecanismos que podem estar sendo recrutados para compensar a deformidade. Considerando esses fatores, é possível definir os objetivos para a correção cirúrgica visando obter melhora clínica.

Descritores: Escoliose; Envelhecimento; Classificação; Mau alinhamento ósseo.

\section{RESUMEN}

La deformidad de la columna vertebral de adultos es una enfermedad compleja que representa un problema de salud pública con un profundo impacto en la sociedad. Al evaluar el paciente, no sólo los aspectos clínicos y radiográficos son esenciales, sino también una clara comprensión de las necesidades y expectativas individuales. Para preparar el plan de tratamiento, es necesario cuantificar el dolor y la discapacidad del paciente, además de la alineación espinopélvica, teniendo en cuenta los mecanismos que pueden ser reclutados para compensar la deformidad. Teniendo en cuenta estos factores, se puede establecer objetivos para la corrección quirúrgica con el fin de obtener una mejoría clínica.

Descriptores: Escoliosis; Envejecimiento; Clasificación; Desviación ósea.

\section{INTRODUCTION}

Interest in Adult Spine Deformity (ASD) has grown over the past decade. This is in line with the demographic shift observed in the majority of the countries around the world, with the number of elderly individuals (i.e. over 60 years) increasing to unprecedented levels, as high as $60 \%$ in some studies. ${ }^{1-3}$ Considering the Brazilian population, a recent study presented an overall spine deformity incidence of $18.5 \%$, which increased to $28.8 \%$ in subjects over 60 years of age. ${ }^{4}$ As a chronic cascade, spinal deformity is associated with degenerative conditions and malalignment between the vertebrae, and is correlated with patient reported pain and disability. It was recently demonstrated that ASD can have a debilitating impact on health, often surpassing the levels of disability associated with more common chronic diseases. ${ }^{5}$ Pellisé et al. ${ }^{6}$ analyzing data from records of individuals in eight industrialized countries (three continents) compared the relative burden of 766 patients who met the inclusion criteria for ASD with 24,936 patients with four chronic conditions (arthritis, chronic lung disease, diabetes and congestive heart failure). They found that the global burden of ASD was huge compared with the other self-reported chronic conditions.

Disability associated with the ASD is mainly due to sagittal malalignment, but the occurrence of neurological compression is also prevalent in patients with degenerative scoliosis. ${ }^{7}$ At least one level of severe foraminal stenosis was identified in $97 \%$ of patients, and canal stenosis in $42 \%$. Of the patients in an ASD database, $88 \%$ had radiculopathy (VAS for leg pain $>0$ ). ${ }^{8}$ The neurological symptoms and deficits have demonstrated an association with operative management conduct; patients who elected surgery were significantly more likely to have radicular weakness and severe radicular pain than those who did not. ${ }^{8}$ 
This article provides an overview of the main concepts of ASD, including the diagnostic, radiographic, and clinical evaluation and treatment planning for spinal deformity surgery. It also gives an overview of what patients can expect concerning their treatment.

\section{Radiographic evaluation and quality of life}

in contrast to adolescent idiopathic scoliosis, where cosmetics and progression of the deformity guide the management, in patients with ASD the most important considerations for treatment relate to pain and disability. ${ }^{9}$ Several studies have underlined the impact of radiographic sagittal plane malalignment on patient self-reported quality of life. ${ }^{10-12}$ This finding was the premise for the recent SRS-Schwab Classification of adult spinal deformity that integrated radiographic parameters correlating with poor Health-Related Quality of Life (HRQOL). ${ }^{13}$

The SRS-Schwab classification (Figure 1) includes a curve type descriptor and three sagittal spinopelvic modifiers that reflect intrinsic components of the sagittal deformity. These modifiers are assessed using the following radiographic parameters: Sagittal vertical axis (SVA), pelvic tilt (PT), and pelvic incidence minus lumbar lordosis mismatch (PI-LL). Curve types include: $\mathrm{T}$ (thoracic major curve $>30^{\circ}$, curve apex at T9 or cranial), L (lumbar or thoracolumbar major curve $>30^{\circ}$, curve apex at T10 or caudal), D (double major curve, in which each curve is $>30^{\circ}$ ), and $\mathrm{N}$ (normal; no coronal curve $>30^{\circ}$ ). The applicability of those modifiers has been demonstrated as change in PT, SVA and PI-LL were responsive to changes in self-reported clinical outcomes at 1 year after treatment. ${ }^{14}$

The clinical relevance of the SRS-Schwab classification was demonstrated by the correlation with severity of the disease and with the treatment decision. ${ }^{15}$ Patients with primary sagittal deformity (Type N) had significantly greater disability and were more likely to present with history of spinal surgery than patients with coronal deformity alone. Regarding surgical strategy, patients with a primary sagittal deformity were significantly more likely to be treated with a major osteotomy and iliac fixation. These patients had poorer sagittal spinopelvic modifiers, according to the SRS-Schwab classification. ${ }^{15}$

Recently, Protopsaltis et al. introduced the T1 Pelvic Angle (TPA), a novel angular measurement of global sagittal spinal deformity established for Adult Spine Deformity. ${ }^{16,17}$ (Figure 2) The TPA is subtended by a line from the femoral heads to the center of the T1 vertebral body and a line from the femoral heads to the center of the superior sacral endplate. The TPA proved to be related to both sagittal vertical axis and pelvic tilt, providing information on both global spinal alignment and position of the pelvis, as a compensatory mechanism, with only one measurement parameter. A correlation was demonstrated

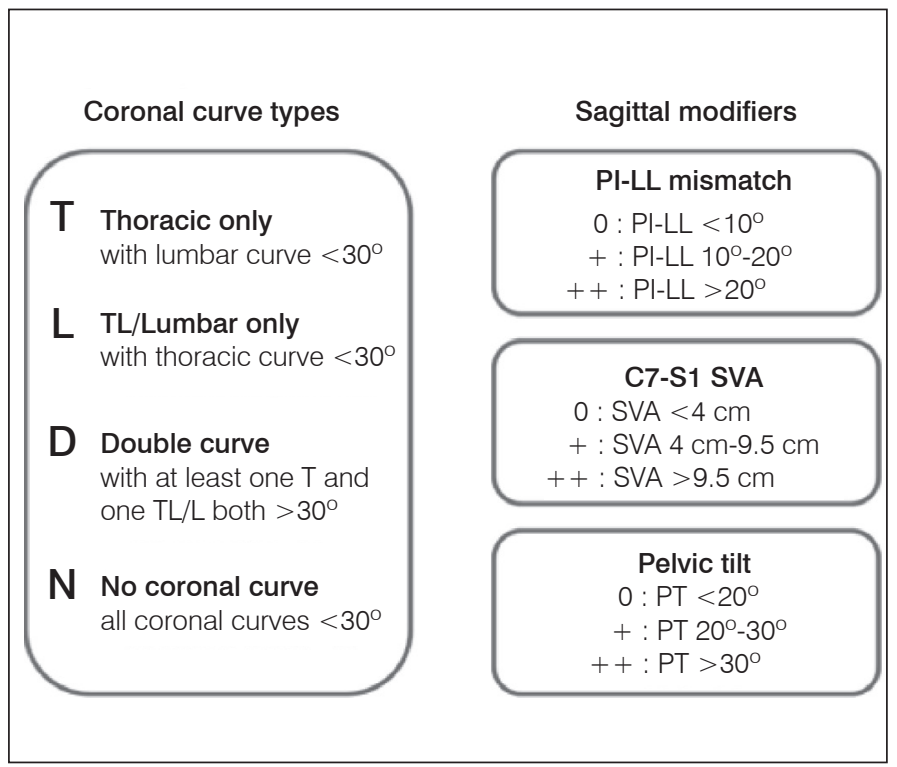

Figura 1. SRS-Schwab Classification of Adult Spine Deformity.

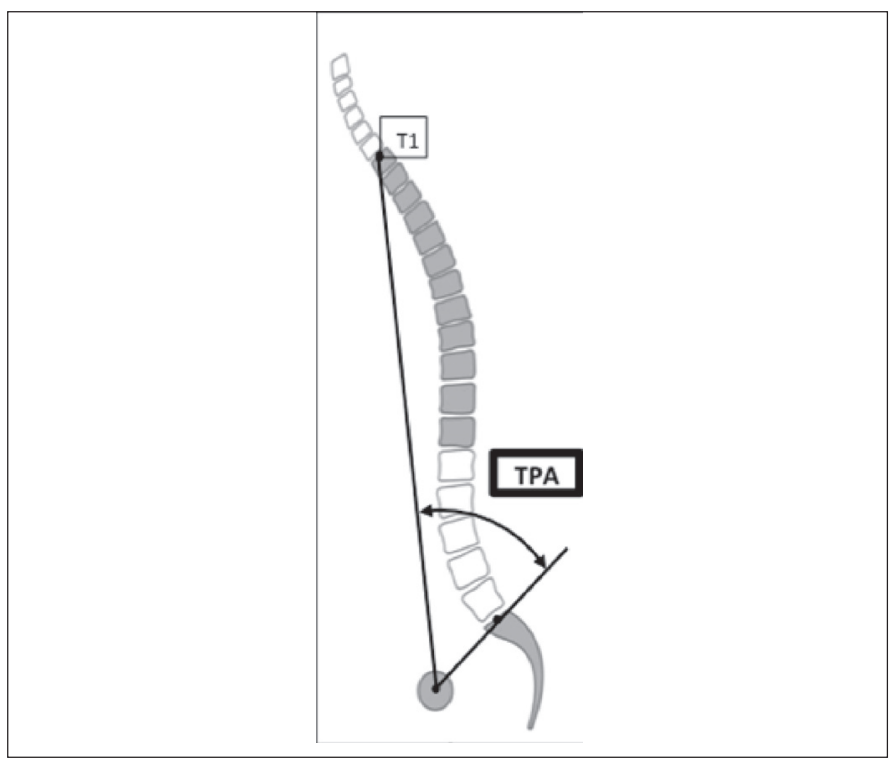

Figura 2. T1 Pelvic Angle (TPA) defined as the angle between the line from the centroid of $\mathrm{T} 1$ to the femoral head axis and the line from the femoral head axis to the middle of the $\mathrm{S} 1$ endplate.

between TPA and health-related quality of life in patients with adult spinal deformity.

Despite the correlation of these radiographic parameters discussed above and the patient's self-reported Quality of Life, the current methods of assessing HRQOL generally focus on more medical and functional outcomes, with little regard for the patient's perspective. A change in a patient's HRQOL score may not reflect a true change in a patient's specific perception of what is most important to them. Therefore, it is necessary to define how much disability is tolerable and acceptable, in order to define the treatment target. The concept of "Clinically Important Difference" intends to overcome the pitfall of "statistical significant difference", since a difference may be statistically significant based simply on numerical value. ${ }^{18}$ A clinically important difference is obtained when the treatment represents a relevant change for a patient, such that they would repeat the same treatment choice. ${ }^{18}$ The Minimal Clinically Important Difference (MCID) is a threshold value for such a change, and any amount of change greater than the MCID threshold is considered to be substantial or important in relation to the treatment choice.

\section{Full body analysis}

with the development of spinal deformity analysis, specifically in relation to sagittal plane alignment, there have been advances in the treatment of patients with ASD. Since the publication of the work of Vidal and Marnay, ${ }^{19}$ there has been increased interest in investigating the relationship between global spinal alignment and pelvic position in the standing position. The concept of "conus of economy" presented by Dubousset ${ }^{20}$ relates to a narrow range within which the body can remain balanced without external support and using minimal effort. This concept was supported by a study assessing the gravity line (GL) and foot position regarding the spinal alignment in asymptomatic volunteers. ${ }^{21}$ It was observed that when the $\mathrm{C} 7$ plumbline shifts anteriorly, the pelvis moves posteriorly (a combination of pelvic retroversion and knee flexion) in relation to the heels. As a result, the GL location in relation to the heels remains constant. Similar behavior of pelvic retroversion and posterior shift in relation to the feet with increasing SVA, but with no difference in GL-heel offset, was observed in a study that included both asymptomatic subjects and symptomatic patients. ${ }^{22}$

In order to maintain a center of mass (GL) in close relation to the feet, keeping the "conus of economy" when anterior spinal malalignment is present, several compensatory mechanisms can be recruited. ${ }^{23-25}$ The identification and graduation of those mechanisms 
allows a true interpretation of the deformity, and needs to be considered when planning deformity correction, in order to achieve optimal postoperative alignment. ${ }^{25}$ Many of the compensatory mechanisms are observed in the spine and pelvis (cervical hyperlordosis, reduction of thoracic kyphosis and pelvic translation and retroversion), and these can be easily recognized on full-spine X-ray. ${ }^{22,23}$ Nevertheless, other mechanisms involve the lower limbs, including changes in the hip, knee and ankle positions, ${ }^{23-26}$ which have not been accurately assessed with conventional spinal images.

With the development of the EOS system, ${ }^{27}$ a form of low-dose irradiation biplanar stereoradiographic imaging, full-body (head to feet) analysis in the standing position is now possible, allowing a fuller understanding of how each patient uses various mechanisms to compensate for spinal malalignment. ${ }^{23,25}$ (Figure 3) In a study describing full-body alignment in a large population with spinal pathologies, researchers observed loss of LL, forward trunk inclination (higher T1 Spinopelvic Inclination Angle and high SVA), and compensatory mechanisms such as pelvic tilt, pelvic posterior shift and knee flexion. ${ }^{25}$ There were also significant correlations between lower-limb parameters and pelvic shift, PT, TPA and SVA, emphasizing the role of lower-limb compensatory mechanisms against disability in patients with spinal malalignment. All these compensatory mechanisms should be assessed in the global care of ASD patients and considered in preoperative planning, emphasizing the usefulness of full-body EOS analysis.

Since the clinical impact of sagittal alignment is dependent of both the severity of the intrinsic spinal deformity and the inability to recruit compensatory mechanisms, it can be helpful to define an overall parameter that includes reflection of both disability status and compensatory mechanisms. The Global Sagittal Angle (GSA) was recently introduced as the angle subtended by a line from the midpoint of the femoral condyles to the center of $\mathrm{C7}$, and a line from the midpoint of the femoral condyles to the posterior superior corner of the $S 1 .{ }^{28}$ (Figure 4) In a retrospective review of 143 patients with ASD who underwent EOS full-body X-rays, significant correlation of the GSA with Oswestry Disability Index (ODI), SRS-22, PT, SVA, TPA and lower limb alignment was identified. GSA significantly increased when TPA increased, with a concurrent decrease in PT, similar to that observed with the ODI. This study presents GSA as a significant and clinically relevant parameter that quantifies both spinal deformity and disability, even in patients with alternative compensation mechanisms. ${ }^{28}$

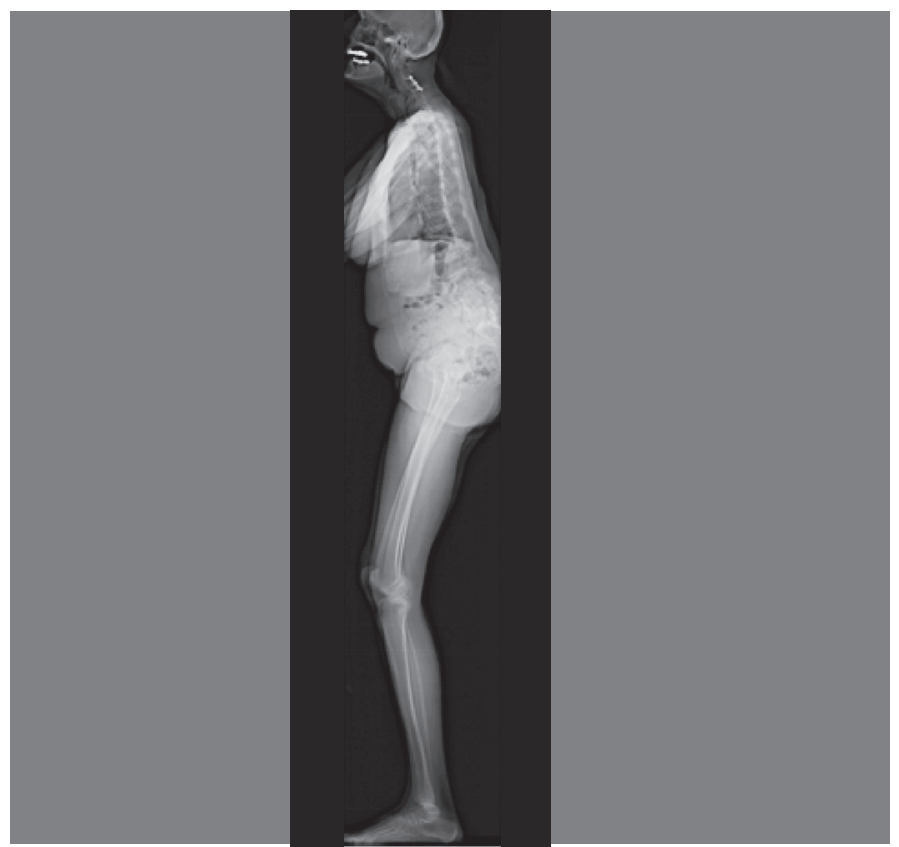

Figura 3. Full body (head to feet) analysis in the standing position.

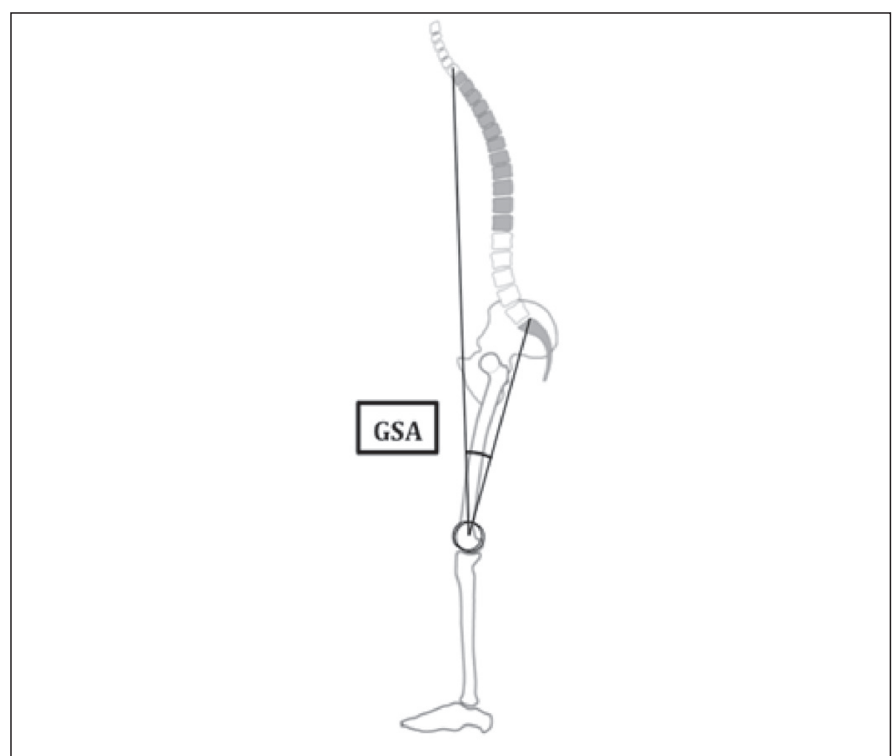

Figura 4. Global Sagittal Angle (GSA) defined as the angle subtended by a line from the midpoint of the femoral condyles to the center of $\mathrm{C} 7$, and a line from the midpoint of the femoral condyles to the posterior superior corner of the S1.

\section{Goals for spinal alignment and outcomes}

The aim of the treatment of patients with ASD is mostly to improve function, provide relief of back and leg pain, and thereby improve the disability. It is necessary to assess whether the treatment modality provides the benefit expected by the patient. The definition of MCID would ideally provide a specific threshold to serve as a treatment goal. The success of treatment would be measured by the proportion of patients who reach MCID, as opposed to the average change in a group of patients. ${ }^{18}$

Nevertheless, in the planning of the treatment, is difficult to establish the surgical indication and select the optimal corrective approaches. Therefore, effective surgical treatment of ASD not only requires a clear understanding of the factors that generate pain and disability, but also defined targets for approaches to address these factors. Schwab and colleagues established three radiographic parameters with clinical relevance, which can predict patient disability and provide a guide for patient assessment for appropriate therapeutic decision making. ${ }^{12}$ The thresholds of the radiographical parameters for predicting severe disability, defined as an ODI of more than $40,{ }^{29}$ were: $\mathrm{PT}=22^{\circ}, \mathrm{SVA}=47 \mathrm{~mm}$ and $\mathrm{PI}-\mathrm{LL}=11^{\circ}$. In regard to the mismatch between $\mathrm{PI}$ and $\mathrm{LL}$, the formula $\mathrm{PI}-\mathrm{LL}<10^{\circ}$ is useful for patients with Thoracic Kyphosis (TK) values within the normal range. However, in cases with abnormal TK, a modified and validated formula to estimate optimal regional alignment to achieve optimal global alignment is required: $\mathrm{LL}=(\mathrm{PI}+\mathrm{TK}) / 2+10 .{ }^{30}$

TPA, an angular and non-linear measurement that does not require calibration of the radiograph, has been shown to be a useful preoperative planning tool. ${ }^{17}$ TPA is related to both pelvic tilt and sagittal vertical axis, radiographic parameters already used as thresholds in prediction for ASD surgical corrective treatment. Linear regression analysis demonstrated that a TPA of $20^{\circ}$ corresponded to severe disability (ODI more than 40), and the meaningful change in TPA corresponding to one MCID on the ODI was $4.1^{\circ}$. An ODI score of 20 points, which is considered to be the cutoff for minimal disability, ${ }^{29}$ corresponded to a TPA of $14^{\circ}$, and the target for the preoperative planning should be to achieve a TPA $<14^{\circ}$.

While these radiographic parameter thresholds are well-established, presenting clinically relevant impact on the outcome of ASD patients, the patients' age related changes was not accounted for in determining these thresholds. In a prospective analysis of a multicenter database including 833 patients, spinopelvic radiographic thresholds (SVA, PT and PI-LL) increased with patients' age. Data suggest that preoperative surgery planning and patient counseling should consider 
patient age. ${ }^{31}$ Schwab et al. ${ }^{32}$ investigated postoperative alignment parameters and HRQOL to determine the validity of targets of correction according to patient age. The team used linear regression analysis of the radiographic parameters (PT, $\mathrm{PI}-\mathrm{LL}$, and SVA) in relation to age and HRQOL (ODI and SF-36 PCS) to provide age-stratified thresholds for radiographic parameters. They observed that ideal alignment targets should account for age, with younger patients requiring more rigorous alignment objectives than older patients.

Although many publications have presented benefits of surgical treatment for ASD, with deformity correction through those radiographic parameters targets discussed above, high-quality studies comparing operative and nonoperative treatment modalities have historically been limited. The first multicenter, prospective analysis of consecutive ASD patients, from 11 sites across the United States, to compare minimum 2-year outcomes for operative and nonoperative treatment (not a randomized study, but the patients chose either operative or nonoperative treatment), was recently published. ${ }^{33}$ At baseline, patients choosing operative treatment had significantly poorer HRQOL based on all the measurements assessed $(P<.001)$ and had worse deformity, based on PT, SVA and PI-LL ( $<$.002). At the minimum 2-year follow-up, operative patients had significant improvement in all HRQOL measurements $(P$ $<$.001). However nonoperative patients had only mild improvements in SRS-22r pain $(P=.04)$ and satisfaction $(P<.001)$ domains. Operative and nonoperative patients were further propensity matched with the baseline ODI, SRS-22r, thoracolumbar/lumbar Cobb angle, PI-LL and leg pain score. Operative patients had significantly better HRQOL at follow-up for all the measurements assessed $(P<.001)$, except the SF-36 mental component score $(P=.06)$. These data showed that operative treatment for ASD can provide a significant improvement in HRQOL, while nonoperative treatment, by contrast, tends to maintain the current levels of pain and disability. ${ }^{33}$

\section{FINAL CONSIDERATIONS}

ASD represents a growing public health issue with deep impact on society. It is complex to precisely recognize, understand and decide on ideal treatment for an individual patient. Recent research has emphasized the involvement of the entire spine, pelvis and even lower limbs in regional spinal deformity. This requires full radiographic analysis, to recognize the compensatory mechanisms acting in each spinal pathology case. There have been great advances in ASD classification, with clinical relevance, making it an effective tool in treatment decision. Radiographic parameters have defined thresholds for HRQOL outcomes, but future studies of sagittal radiographic parameter correction goals for individual age groups are necessary. There is good data to support the benefits of operative treatment for selected ASD patients over nonoperative management, but there is a lack of detailed data on the specific cases in which non-operative care is best indicated.

All authors declare no potential conflict of interest related to this article.

AUTHOR CONTRIBUTIONS: The manuscript "ADULT SPINE DEFORMITY - AN OVERVIEW OF RADIOGRAPHIC AND CLINICAL CONSIDERATIONS" is an update article with has three authors. Each author made significant individual contributions to this manuscript. RP and BD wrote the manuscript, with a final revision by the author FS. All the authors contributed equally to the intellectual design of the manuscript, and approved the final version.

\section{REFERENCES}

1. Schwab F, Dubey A, Pagala M, Gamez L, Farcy JP. Adult scoliosis: a health assessment analysis by SF-36. Spine (Phila Pa 1976). 2003;28(6):602-6.

2. Schwab F, Dubey A, Gamez L, El Fegoun AB, Hwang K, Pagala M, et al. Adult scoliosis: prevalence, SF-36, and nutritional parameters in an elderly volunteer population. Spine (Phila Pa 1976). 2005;30(9):1082-5.

3. Schwab FJ, Lafage V, Farcy JP, Bridwell KH, Glassman S, Shainline MR. Predicting outcome and complications in the surgical treatment of adult scoliosis. Spine (Phila Pa 1976). 2008;33(20):2243-7.

4. Barreto MVA, Pratali RR, Barsotti CEG, Santos FPE, Oliveira CEA, Nogueira MP. Incidence of spinal deformity in adults and its distribution according SRS-Schwab classification. Coluna/Columna. 2015(14):93-6.

5. Bess S, Line B, Fu KM, McCarthy I, Lafage V, Schwab F, et al. The health impact of symptomatic adult spinal deformity: comparison of deformity types to United States population norms and chronic diseases. Spine (Phila Pa 1976). 2016;41(3):224-33.

6. Pellisé F, Vila-Casademunt $A$, Ferrer M, Domingo-Sàbat $M$, Bagó J, Pérez-Grueso FJ, et al. ESSG. Impact on health related quality of life of adult spinal deformity (ASD) compared with other chronic conditions. Eur Spine J. 2015;24(1):3-11.

7. Fu KM, Rhagavan P, Shaffrey Cl, Chernavvsky DR, Smith JS. Prevalence, severity, and impact of foraminal and canal stenosis among adults with degenerative scoliosis. Neurosurgery. 2011:69(6):1181-7.

8. Smith JS, Fu KM, Urban P, Shaffrey Cl. Neurological symptoms and deficits in adults with scoliosis who present to a surgical clinic: incidence and association with the choice of operative versus nonoperative management. J Neurosurg Spine. 2008;9(4):326-31.

9. Bess S, Boachie-Adjei O, Burton D, Cunningham M, Shaffrey C, Shelokov A, et al. Pain and disability determine treatment modality for older patients with adult scoliosis, while deformity guides treatment for younger patients. Spine (Phila Pa 1976). 2009;34(20):2186-90.

10. Glassman SD, Bridwell K, Dimar JR, Horton W, Berven S, Schwab F. The impact of positive sagittal balance in adult spinal deformity. Spine (Phila Pa 1976). 2005:30(18):2024-9.

11. Lafage V, Schwab F, Patel A, Hawkinson N, Farcy JP. Pelvic tilt and truncal inclination: two key radiographic parameters in the setting of adults with spinal deformity. Spine (Phila Pa 1976). 2009;34(17):E599-606

12. Schwab FJ, Blondel B, Bess S, Hostin R, Shaffrey Cl, Smith JS, et al. Radiographical spinopelvic parameters and disability in the setting of adult spinal deformity: a prospective multicenter analysis. Spine (Phila Pa 1976). 2013:38(13):E803-12.

13. Schwab F, Ungar B, Blondel B. Scoliosis research society-Schwab adult spinal deformity classification-a validation study. Spine (Phila Pa 1976). 2012;37:1077-82.

14. Smith JS, Klineberg E, Schwab F, Shaffrey Cl, Moal B, Ames CP, et al. Change in classification grade by the SRS-Schwab Adult Spinal Deformity Classification predicts impact on health-related quality of life measures: prospective analysis of operative and nonoperative treatment. Spine (Phila Pa 1976). 2013;38(19):1663-71.

15. Terran J, Schwab F, Shaffrey Cl, Smith JS, Devos P, Ames CP, et al. The SRS-Schwab adult spinal deformity classification: assessment and clinical correlations based on a prospective operative and nonoperative cohort. Neurosurgery. 2013;73(4):559-68.

16. Ryan DJ, Protopsaltis TS, Ames CP, Hostin R, Klineberg E, Mundis GM, et al; International Spine Study Group.. T1 pelvic angle (TPA) effectively evaluates sagittal deformity and assesses radiographical surgical outcomes longitudinally. Spine (Phila Pa 1976). 2014;39(15):1203-10.
17. Protopsaltis T, Schwab F, Bronsard N, Smith JS, Klineberg E, Mundis G, et al. TheT1 pelvic angle, a novel radiographic measure of global sagittal deformity, accounts for both spinal inclination and pelvic tilt and correlates with health-related quality of life. J Bone Joint Surg Am. 2014;96(19):1631-40.

18. Copay AG, Subach BR, Glassman SD, Polly DW Jr, Schuler TC. Understanding the minimum clinically important difference: a review of concepts and methods. Spine J. 2007:7(5):541-6

19. Vidal J, Marnay T. Sagittal deviations of the spine, and trial of classification as a function of the pelvic balance. Rev Chir Orthop Reparatrice Appar Mot. 1984;70(Suppl 2):124-6.

20. Dubousset J. Three-Dimensional analysis of the scoliotic deformity. In: Weinstein SL, editor. Pediatric spine: principles and practice. New York, NY: Raven Press: 1994 p. 479-96.

21. Schwab F, Lafage V, Boyce R, Skalli W, Farcy JP. Gravity line analysis in adult volunteers: age-related correlation with spinal parameters, pelvic parameters, and foot position. Spine (Phila Pa 1976). 2006;31(25):E959-67.

22. Lafage V, Schwab F, Skalli W, Hawkinson N, Gagey PM, Ondra S, et al. Standing balance and sagittal plane spinal deformity: analysis of spinopelvic and gravity line parameters. Spine (Phila Pa 1976). 2008;33(14):1572-8.

23. Barrey C, Roussouly P, Le Huec JC, D'Acunzi G, Perrin G. Compensatory mechanisms contributing to keep the sagittal balance of the spine. Eur Spine J. 2013;22(Suppl 6):S834-41.

24. Obeid I, Hauger O, Aunoble S, Bourghli A, Pellet N, Vital JM. Global analysis of sagittal spinal alignment in major deformities: correlation between lack of lumbar lordosis and flexion of the knee. Eur Spine J. 2011;20(Suppl 5):681-5.

25. Ferrero E, Liabaud B, Challier V, Lafage R, Diebo BG, Vira S, et al. Role of pelvic translation and lower-extremity compensation to maintain gravity line position in spinal deformity. J Neurosurg Spine. 2016:24(3):436-46.

26. Barrey C, Roussouly P, Perrin G, Le Huec JC. Sagittal balance disorders in severe degenerative spine. Can we identify the compensatory mechanisms? Eur Spine J. 2011;20(Suppl 5):626-33.

27. Dubousset J, Charpak G, Dorion I, Skalli W, Lavaste F, Deguise J, et al. Le systeme EOS Nouvelle imagerie osteo- articulaire basse dose en position debout. Radioprotection. 2005;40(2):245-55.

28. Diebo BG, Oren JH, Vira S. Global sagittal Angle (GSA): a step toward full body assess ment for spinal deformity. In: Annual Meeting, Minneapolis, USA, 2015.

29. Fairbank JC, Couper J, Davies JB, O'Brien JP. The Oswestry low back pain disability questionnaire. Physiotherapy. 1980:66(8):271-3.

30. Schwab FJ, Diebo BG, Smith JS, Hosin RA, Shaffrey Cl, Cunningham ME, et al. Fine-tuned surgical planning in adult spinal deformity: Determining the lumbar lordosis necessary by accounting for both thoracic kyphosis and pelvic incidence. Spine J. 2014;14:S73.

31. Scheer JK, Smith JS, Lafage V, Shaffrey $\mathrm{Cl}$, Lafage $\mathrm{R}$, Klineberg $\mathrm{E}$, et al. Spinal pelvic radiographic thresholds for regional lumbar disability are age dependent: analysis of multicenter database of 833 patients. Clin Neurosurg. 2014;61(1):209.

32. FJ Schwab, R Lafage, BB Liabaud, Diebo BG, Smith JS, Hostin RA, et al. Does one size fit all? Defining spinopelvic alignment thresholds based on age. Spine J. 2014;14(11):S120-1.

33. Smith JS, Lafage V, Shaffrey Cl, Schwab F, Lafage R, Hostin R, et al. Outcomes of operative and nonoperative treatment for adult spinal deformity: a prospective, multicenter, propensity-matched cohort assessment with minimum 2-year follow-up. Neurosurgery. 2016;78(6):851-61 